\title{
O ESTADO DA ARTE DO CAMPO TEMÁTICO EDUCAÇÃO AMBIENTAL E MÍDIA NA PESQUISA ACADÊMICA BRASILEIRA (2010 A 2018)
}

\author{
Bety Rita Rodrigues Ramos ${ }^{1}$ \\ Giovana Galvão Tavares ${ }^{2}$ \\ Vivian da Silva Braz ${ }^{3}$
}

Resumo: Este trabalho traça o "estado da arte" da temática Educação Ambiental e mídia na pesquisa acadêmica brasileira, no período de 2010 a 2018. A metodologia adotada foi bibliográfica e análise de dados. Foram analisados 13 trabalhos selecionados no banco de dados da CAPES (Catálogo de Dissertações e Teses), e na BDTD (Biblioteca Digital Brasileira de Teses e Dissertações). O estudo aponta aspectos como: temática pouco explorada; educomunicação como abordagem predominante; trabalhos interdisciplinares; tratamento superficial da mídia aos temas ambientais; importância da mídia na divulgação da temática; e também a existência de aspectos ideológicos, políticos e mercadológicos que envolvem os meios de comunicação de massa.

Palavras-chave: Educação Ambiental; Mídia; Estado da Arte.

1 Jornalista do Instituto Brasília Ambiental (IBRAM). Aluna do Curso de Mestrado do Programa de Pós-Graduação em Sociedade, Tecnologia e Meio Ambiente (PPG STMA) e membro do Núcleo de Educação Ambiental (NEA), ambos do Centro Universitário de Anápolis, Goiás. Email: betyritaramos@gmail.com

2 Coordenadora do NEA e professora titular do PPG STMA, ambos do Centro Universitário de Anápolis, Goiás. E-mail: gio.tavares@gmail.com

3 Coordenadora e professora titular do PPG STMA, membro do NEA, ambos do Centro Universitário de Anápolis, Goiás. E-mail: vsbraz@gmail.com 


\section{Introdução}

Que a mídia tem papel estratégico na Educação Ambiental (EA) é praticamente consenso entre estudiosos do assunto. Conforme Bueno (2007) a função do jornalismo é mais que tão somente informativa e política. Para o autor o jornalismo também tem a função pedagógica, que contempla a explicitação das causas, soluções e os caminhos para a superação dos problemas por meio da disseminação de informações, conhecimentos e vivências que subsidiem o cidadão para o questionamento, por exemplo, do debate ambiental.

Côgo (2015) ressalta que o jornalismo tem papel fundamental na problematização sobre a questão ambiental. Para ela, as práticas jornalísticas devem ter como finalidade a construção da crítica e o respeito à diversidade cultural, "rejeitando proselitismos, debatendo publicamente temas de relevância social, assegurando a expressão de ideias, opiniões e pontos de vista divergentes e socializando a produção do conhecimento" (CÔGO, 2015, p. 22).

Dentro dessa perspectiva, este trabalho objetiva apurar o estado da arte ou estado do conhecimento, na produção acadêmica brasileira, do tema 'EA e Mídia'. A proposta metodológica tem caráter inventariante e descritivo e é imprescindível no processo de mapeamento da produção bibliográfica do campo de estudo em questão. Pesquisamos, especificamente, o viés de EA nas matérias jornalísticas cotidianas sobre os temas relacionados às questões ambientais.

Concordamos com Tristão (2013) que a informação é um agente de produção de sentidos em meio à rede de relações, práticas e interações sobre a cultura-natureza. Portanto, conforme Soares $(1987$, p.3),

é necessária no processo de evolução da ciência, afim de que se ordene periodicamente o conjunto de informações e resultados já obtidos, ordenação que permita indicação das possibilidades de integração de diferentes perspectivas, aparentemente autônomas, a identificação de duplicações ou contradições, e a determinação de lacunas e vieses.

No empenho de ordenarmos determinada produção de conhecimento, também é possível "perceber que as pesquisas crescem e se espessam ao longo do tempo; ampliam-se em saltos ou em movimentos contínuos; multiplicam-se, mudando os sujeitos e as forças envolvidas" (FERREIRA, 2002, p.265).

Diante do exposto, este artigo busca colaborar para ampliar o debate sobre a EA e Mídia, além de convidar o (a) leitor (a) a realizar estudo sobre o estado da arte da EA e sua interconexão com diferentes campos de conhecimento (EA e saúde; EA e Gestão de Empresas, entre outros). 


\title{
Metodologia
}

A pesquisa estado da arte é bibliográfica e de análise de dados. Ela visa trazer à tona a produção quantitativa e qualitativa de um campo de pesquisa com o objetivo de analisar a produção existente e descortinar cenários futuros. Como nos lembra Ferreira (2002, p. 258),

\begin{abstract}
essas pesquisas também são reconhecidas por realizarem uma metodologia de caráter inventariante e descritivo da produção acadêmica e científica sobre o tema que busca investigar, à luz de categorias e facetas que se caracterizam enquanto tais em cada trabalho e no conjunto deles, sob os quais o fenômeno passa a ser analisado.
\end{abstract}

Isto posto, nosso primeiro passo foi definir o período de produção acadêmica a ser revisitado. Fundamentados no fator atualidade, definimos como período de pesquisa os últimos oito anos de produção, portanto, de 2010 a 2018, posteriormente, definimos os bancos de dados, optando pelo da Capes (Catálogo de Teses e Dissertações) e da BDTD (Biblioteca Digital Brasileira de Teses e Dissertações).

No passo seguinte definimos os grupos de descritores a serem utilizados nos bancos de dados. Em um primeiro momento pesquisamos apenas a combinação de palavras "EA e Mídia" e encontramos 420 trabalhos na Capes, e 227 na BDTD, dos quais foram selecionados 04 trabalhos considerando a maior proximidade com o tema a ser pesquisado.

Entendemos que 04 trabalhos significava um número reduzido, e acrescentamos outros grupos de descritores: "EA e Jornalismo"; "EA e Revistas"; e, "EA e Rádio". O resultado foi um total de 2.537 dissertações e teses em resposta aos grupos de descritores nos bancos de dados.

Com a combinação de palavras EA e Revistas localizamos 1.439 trabalhos no Capes, entre os quais selecionamos 01, e 285 na BDTD, dos quais selecionamos 03. Com as palavras EA e Rádio obtivemos 601 achados no Capes, sendo que apenas 01 desses trabalhos foi selecionado, e 212 na BDTD, porém sem nenhum se enquadrar em nosso critério de seleção, que foi, a partir da leitura do título, resumo ou parte dele, detectar aspectos mais próximos possíveis do nosso tema de pesquisa, considerando o entrelaçar dos conceitos EA e Mídia.

Com base na seleção dos trabalhos, sistematizamos as informações gerais que caracterizam cada um deles, buscando observar os seguintes aspectos: a) tendência do campo de pesquisa, b) interdisciplinaridade; c) formação do pesquisador; d) áreas dos cursos de pós-graduação; e) local de origem dos trabalhos; f) ano de produção; g) objetivo; h) metodologia; i) discussão; j) e resultado. 
Para facilitar o nosso entendimento da tendência da discussão EA e Mídia, com base na análise das dissertações e teses, as dividimos em quatro categorias: a) Educomunicação; b) EA na Mídia especializada em meio Ambiente; c) EA na Mídia não especializada; e, d) EA na Mídia especializada em educação.

\section{Resultados e Discussão}

As dissertações e teses encontradas evidenciam que existe uma farta produção de pesquisas sobre EA isolada e também sobre os vários instrumentos da mídia como jornais, revista, rádio, entre outros. Porém, quando se parte para o campo que entrelaça esses dois temas, os números diminuem significativamente $e$, mais ainda, quando se busca trabalhos que estudem perspectivas da mídia como educadora ambiental na sua produção jornalística cotidiana.

Neste universo de teses e dissertações encontradas foram selecionados somente treze trabalhos. Estes dados revelam que o número de pesquisas na intersecção entre EA e Mídia apresenta participação inferior a $0,5 \%$. Por outro lado, é perceptível que este campo desperta interesse em pesquisadores de diferentes formações e de programas de pós-graduação de áreas diversas.

Os trabalhos que selecionamos são de programas de pós-graduação: a) Desenvolvimento Sustentável, apenas 01; b) Educação Científica e Tecnológica, também 01; c) Educação, 02 trabalhos; d) Comunicação Social/Jornalismo, 01; e) Ciências da Saúde e do Ambiente, 02 trabalhos; f) Gestão Ambiental, 01; g) Sustentabilidade e Gestão Ambiental, 01; h) Educação Ambiental, 01; i) Ensino de Ciências Modalidade Física, Química e Biologia; também 01 trabalho; j) Agronegócio e Desenvolvimento, 01; e, Geografia, 01.

Os pesquisadores têm graduações variadas como em jornalismo, arquitetura, engenharia, pedagogia e biologia, entre outras, como mostra Quadro 1.

No Quadro 1 também é possível identificar que $69,23 \%$ são interdisciplinares e $30,77 \%$ são disciplinares. Essa variedade de área de pesquisa, de formação do pesquisador e o quantitativo de cursos interdisciplinares confirmam o caráter de interdisciplinaridade assumido cada vez mais como característica da área ambiental. 
Quadro 1: Quadro da Formação dos pesquisadores, áreas de pesquisa dos Programas de Pós-Graduação, interdisciplinaridade dos Programas e ano de Produção.

\begin{tabular}{|c|c|c|c|c|}
\hline Trabalho & Autor & $\begin{array}{l}\text { Formação } \\
\text { do Autor }\end{array}$ & $\begin{array}{c}\text { Programas de } \\
\text { Pós-Graduação }\end{array}$ & $\begin{array}{c}\text { Ano de } \\
\text { Produção }\end{array}$ \\
\hline $\begin{array}{l}\text { 1.Telejornalismo e Educação } \\
\text { Ambiental: formação do sujeito } \\
\text { consumidor }\end{array}$ & $\begin{array}{c}\text { Cristiane } \\
\text { Leite Pereira }\end{array}$ & Jornalismo & $\begin{array}{l}\text { Desenvolvimento } \\
\text { Sustentável } \\
\text { (Interdisciplinar) }\end{array}$ & 2011 \\
\hline $\begin{array}{l}\text { 2. Mídia como instrumento de } \\
\text { educação e de formação da } \\
\text { consciência ambiental abordagens } \\
\text { na educação tecnológica }\end{array}$ & $\begin{array}{l}\text { Fernando } \\
\text { Teixeira }\end{array}$ & Arquitetura & $\begin{array}{c}\text { Educação } \\
\text { Científica e } \\
\text { Tecnológica } \\
\text { (Interdisciplinar) }\end{array}$ & 2011 \\
\hline $\begin{array}{c}\text { 3. A revista nova escola e as } \\
\text { tendências em Educação } \\
\text { Ambiental }\end{array}$ & $\begin{array}{l}\text { Susana } \\
\text { Mezzari }\end{array}$ & Biologia & $\begin{array}{l}\text { Educação } \\
\text { (Disciplinar) }\end{array}$ & 2012 \\
\hline $\begin{array}{l}\text { 4. O Discurso das Mudanças } \\
\text { Climáticas no Diário Catarinense }\end{array}$ & $\begin{array}{l}\text { Cristian } \\
\text { Madalena } \\
\text { Derosa }\end{array}$ & Jornalismo & $\begin{array}{l}\text { Jornalismo } \\
\text { (Disciplinar) }\end{array}$ & 2013 \\
\hline $\begin{array}{l}\text { 5. Representações Sociais de } \\
\text { Educação Ambiental para } \\
\text { estudantes: Jornalismo como } \\
\text { estratégia pedagógica }\end{array}$ & $\begin{array}{l}\text { Angélica } \\
\text { Aparecida } \\
\text { Silva Arieira }\end{array}$ & Jornalismo & $\begin{array}{l}\text { Ciências da Saúde } \\
\text { e do Ambiente } \\
\text { (Interdisciplinar) }\end{array}$ & 2013 \\
\hline $\begin{array}{l}\text { 6. Comunicação, Cultura e } \\
\text { Linguagem: o rádio como } \\
\text { instrumento para a prática de } \\
\text { Educação Ambiental na Província } \\
\text { do Cunene (República de Angola) }\end{array}$ & $\begin{array}{l}\text { Benedito } \\
\text { Lilongeni } \\
\text { Sipandeni }\end{array}$ & $\begin{array}{l}\text { Ciências da } \\
\text { Comunica- } \\
\text { ção }\end{array}$ & $\begin{array}{l}\text { Gestão Ambiental } \\
\text { (Interdisciplinar) }\end{array}$ & 2013 \\
\hline $\begin{array}{l}\text { 7. Mídia em Educação Ambiental: } \\
\text { O uso do recurso tecnológico } \\
\text { audiovisual no cotidiano escolar }\end{array}$ & $\begin{array}{l}\text { Moysés } \\
\text { Farias das } \\
\text { Chagas }\end{array}$ & $\begin{array}{l}\text { Comunicaç } \\
\text { ão Social - } \\
\text { Rádio e TV }\end{array}$ & $\begin{array}{l}\text { Ciências da Saúde } \\
\text { e do Ambiente } \\
\text { (Interdisciplinar) }\end{array}$ & 2013 \\
\hline $\begin{array}{l}\text { 8. A Prática de Educação } \\
\text { Ambiental no âmbito do ensino } \\
\text { formal: estudos publicados em } \\
\text { revistas Acadêmicas Brasileiras } \\
\text { (2007 a 2012) }\end{array}$ & $\begin{array}{l}\text { Patrícia de } \\
\text { Lourdes } \\
\text { Viegas }\end{array}$ & $\begin{array}{l}\text { Engenharia } \\
\text { Ambiental }\end{array}$ & $\begin{array}{l}\text { Sustentabilidade e } \\
\text { Gestão ambiental } \\
\text { (Interdisciplinar) }\end{array}$ & 2013 \\
\hline $\begin{array}{l}\text { 9. O Telejornalismo Local e seus } \\
\text { Modos de Produzir sentidos em } \\
\text { Educacão Ambiental }\end{array}$ & $\begin{array}{c}\text { Maria de } \\
\text { Fátima Côgo }\end{array}$ & Jornalismo & $\begin{array}{l}\text { Educação } \\
\text { (Disciplinar) }\end{array}$ & 2014 \\
\hline $\begin{array}{l}\text { 10. O Dispositivo da Educação } \\
\text { Ambiental: modos de Constitui-se } \\
\text { Sujeito na Revista Veja }\end{array}$ & $\begin{array}{c}\text { Bárbara } \\
\text { Hees Garré }\end{array}$ & Pedagogia & $\begin{array}{c}\text { Educação } \\
\text { Ambiental } \\
\text { (Interdisciplinar) }\end{array}$ & 2015 \\
\hline $\begin{array}{l}\text { 11. Análise de mídias audiovisuais } \\
\text { sob a perspectiva da Educação } \\
\text { Ambiental crítica e dos professores } \\
\text { da educação básica' }\end{array}$ & $\begin{array}{c}\text { Marcia } \\
\text { Cristina } \\
\text { Bacic }\end{array}$ & Biologia & $\begin{array}{l}\text { Ensino de Ciências } \\
\text { Modalidade Física, } \\
\text { Química e Biologia } \\
\text { (Interdisciplinar) }\end{array}$ & 2015 \\
\hline $\begin{array}{l}\text { 12. Comunicação e Educação } \\
\text { Ambiental: uma análise de } \\
\text { conteúdo da revista XXI Ciência } \\
\text { para a Vida da Embrapa }\end{array}$ & $\begin{array}{c}\text { Fábio Freitas } \\
\text { dos Santos }\end{array}$ & $\begin{array}{l}\text { Engenharia } \\
\text { Ambiental }\end{array}$ & $\begin{array}{l}\text { Agronegócio e } \\
\text { Desenvolvimento } \\
\text { (Interdisciplinar) }\end{array}$ & 2017 \\
\hline $\begin{array}{l}\text { 13. Estado da arte das produções } \\
\text { na Revista Brasileira de Educação } \\
\text { Ambiental de } 2010 \text { a } 2016\end{array}$ & $\begin{array}{l}\text { Angela Maria } \\
\text { Kreuz }\end{array}$ & Geografia & $\begin{array}{c}\text { Geografia } \\
\text { (Disciplinar) }\end{array}$ & 2017 \\
\hline
\end{tabular}

Fonte: Autoras, 2019. 
A interdisciplinaridade é de grande importância para que a EA possa assumir seu papel na edificação de sociedades sustentáveis, e a base para isso é o pensamento crítico e inovador, favorecendo a transformação e a construção de uma sociedade igualitária. A Educação Ambiental não é neutra, mas ideológica, inserindo-se numa perspectiva holística e, revelando assim seu caráter político (TOZONI-REIS, 2002; BARBIERI, 2011).

São diversos olhares e inúmeras e diferentes percepções, o que para vários autores é um dado positivo. Pitanga (2001) defende que a construção de uma racionalidade ambiental demanda a transformação dos paradigmas científicos e a produção de novos conhecimentos, para isso é necessário que haja o diálogo, a hibridação e a integração dos saberes. Leff (2010) ressalta ser a integração de diversos especialistas nas áreas do conhecimento fator que garante uma integração interdisciplinar do conhecimento e cria bases para um desenvolvimento realmente sustentável.

Com relação à análise da produção anual, extraímos da compilação feita na Figura 1 e, evidenciada na Figura 1, que o ano de maior produção foi 2013, quando 04 dos trabalhos selecionados foram produzidos. Em 2011 foram 02, em 2012 apenas 01 e, 2 em 2015. Em 2017 foram 02 e 01 em 2018. Em 2010 e 2016 não teve produção de trabalhos que se aproximassem da temática. Dos trabalhos produzidos em 2014 nenhum atendeu aos quesitos de proximidade do nosso objeto de estudo, portanto, não houve selecionados.

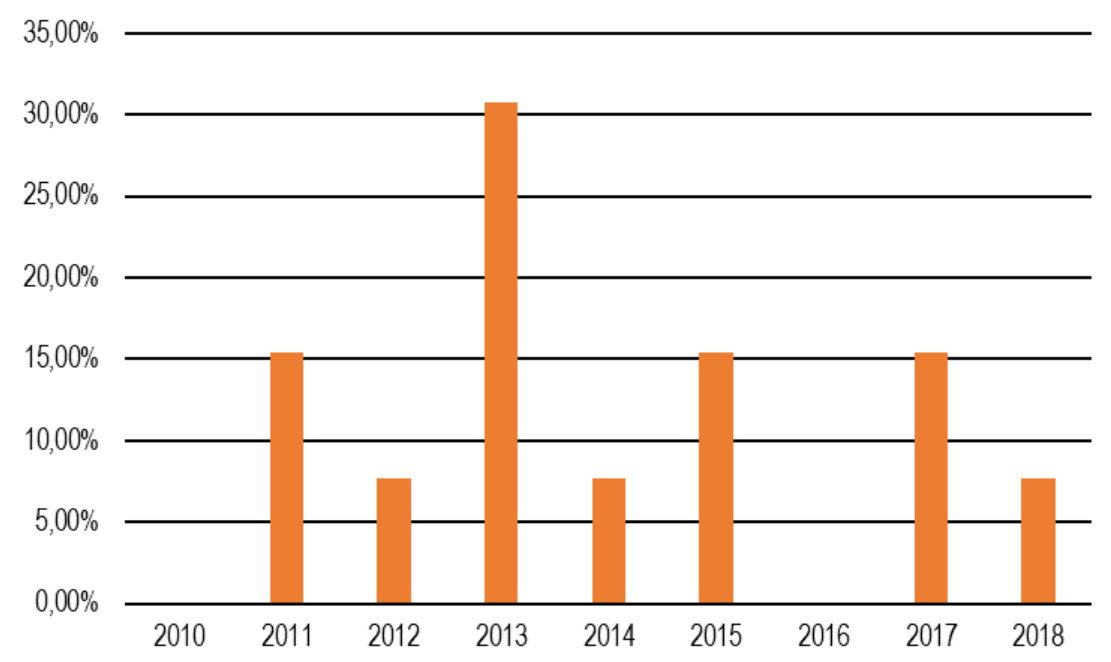

Figura 1: Percentual de trabalhos produzidos anualmente sobre mídia e Educação Ambiental selecionados nos bancos de dados Capes e BDTD, no período entre 2010 e 2018.

Fonte: As Autoras, 2019.

Partindo para a busca de possível motivação de um maior número de pesquisas em 2013, levamos em conta que os 04 trabalhos produzidos neste ano foram em programas de mestrado, e que a dissertação tem seu início de produção, normalmente, dois anos antes de sua publicação, fomos em busca dos fatos da área ambiental no ano de 2011 que possam ter inspirado os pesquisadores. 
O ano de 2011 foi marcado, segundo retrospectivas de vários veículos de comunicação (Revistas Exame, Veja, entre outros), por muitos desastres ambientais relacionados às mudanças climáticas. Os primeiros fatos citados na matéria retrospectiva da área ambiental foram o terremoto no Japão, de nove graus de magnitude, que fez renascer o medo nuclear, e o tsunami de 11 de março no mesmo país. Segundo as notícias divulgadas pela mídia, as duas ocorrências deixaram mais de 20 mil mortos e desaparecidos, além de cidades destroçadas.

A retrospectiva da mídia revelou também que o ano de 2011 entrou para a história como o décimo mais quente desde 1958, quando os cientistas começaram a registrar a temperatura da Terra. No ano de 2011, a Agência Espacial Europeia, a partir das medições dos satélites de observação do planeta, concluiu que a camada de gelo do ártico diminuiu ao menor nível já registrado desde 1970.

O ano de 2011 foi ainda marcado por erupções vulcânicas. Na Europa, o vulcão islandês Grimsvotn, e na América do Sul, o vulcão Puyehue, situado na cordilheira dos Andes, adormecido por mais de 50 anos, entraram em atividade.

No Brasil o ano foi marcado pela tragédia na região serrana do Rio de Janeiro, devido às chuvas que culminaram em muitos deslizamentos de terra, considerado, pela mídia até àquele momento, o mais trágico que já acometeu no país. Foram dezenas de mortos. Além das manifestações registradas na mídia sobre a construção da usina de Belo Monte, no rio Xingu (Pará) e, ainda a votação do Código Florestal Brasileiro no Congresso Nacional.

Com relação à localização regional da produção das pesquisas ficou claro que as Regiões Sul e Sudeste lideram com maior número de trabalhos, como mostra Figura 2.

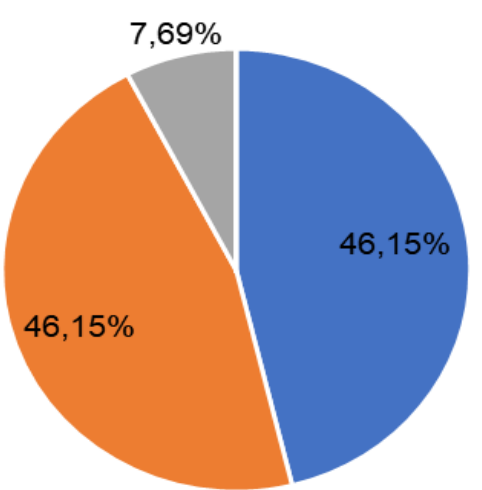

- Sul - Sudeste $=$ Centro Oeste $=$ Norte $\quad$ Nordeste

Figura 2: Percentual da participação, por região, na produção dos trabalhos sobre Educação Ambiental e mídia selecionados nos bancos de dados Capes e BDTD, no período entre 2010 e 2018 .

Fonte: As Autoras, 2019. 
No que se refere à localização das produções por unidades federativas, os estados de Santa Catarina e São Paulo estão à frente. O Quadro 2 apresenta teses e dissertações desenvolvidas em universidades da região Sul, das quais 03 no estado de Santa Catarina, 01 no Rio Grande do Sul e 01 no Paraná. E 06 em universidades da região Sudeste, das quais 03 no estado de São Paulo, 01 no Rio de Janeiro e 01 no Espírito Santo. A região Centro-Oeste responde por 01 produto realizado no Distrito Federal. Nas universidades das regiões Norte e Nordeste não foram registradas produções de trabalhos no período pesquisado.

Quadro 2: Universidades e Estados em que foram produzidos os trabalhos que envolvem a temática Educação Ambiental e Mídia, selecionados nos bancos de dados Capes e BDTD, no período 2010 e 2018.

\begin{tabular}{|c|c|}
\hline Trabalho & Universidade/Estado \\
\hline $\begin{array}{l}\text { 1. Telejornalismo e Educação Ambiental: formação } \\
\text { do sujeito consumidor }\end{array}$ & $\begin{array}{l}\text { Universidade de Brasília (UnB)/ } \\
\text { Brasília }\end{array}$ \\
\hline $\begin{array}{l}\text { 2. Mídia como instrumento de educação e de } \\
\text { formação da consciência ambiental abordagens na } \\
\text { educação tecnológica }\end{array}$ & $\begin{array}{l}\text { Universidade Federal de Santa } \\
\text { Catarina / Santa Catarina }\end{array}$ \\
\hline $\begin{array}{l}\text { 3. A revista nova escola e as tendências em } \\
\text { Educação Ambiental }\end{array}$ & $\begin{array}{l}\text { Universidade do Extremo Sul } \\
\text { Catarinense (UNESC) / Santa Catarina }\end{array}$ \\
\hline $\begin{array}{l}\text { 4. O Discurso das Mudanças Climáticas no Diário } \\
\text { Catarinense }\end{array}$ & $\begin{array}{l}\text { Universidade Federal de Santa } \\
\text { Catarina / Santa Catarina }\end{array}$ \\
\hline $\begin{array}{l}\text { 5. Representações Sociais de Educação Ambiental } \\
\text { para estudantes: Jornalismo como estratégia } \\
\text { pedagógica }\end{array}$ & $\begin{array}{l}\text { Centro Universitário de Volta Redonda } \\
\text { / Rio de Janeiro }\end{array}$ \\
\hline $\begin{array}{l}\text { 6. Comunicação, Cultura e Linguagem: o rádio como } \\
\text { instrumento para a prática de Educação Ambiental na } \\
\text { Província do Cunene (República de Angola) }\end{array}$ & Universidade Positivo (UP) / Paraná \\
\hline $\begin{array}{l}\text { 7. Mídia em Educação Ambiental: O uso do recurso } \\
\text { tecnológico audiovisual no cotidiano escolar }\end{array}$ & $\begin{array}{l}\text { Centro Universitário Plínio Leite/ Rio } \\
\text { de Janeiro }\end{array}$ \\
\hline $\begin{array}{l}\text { 8. A Prática de Educação Ambiental no âmbito do } \\
\text { ensino formal: estudos publicados em revistas } \\
\text { Acadêmicas Brasileiras (2007 a 2012) }\end{array}$ & $\begin{array}{l}\text { Universidade Federal de São Carlos/ } \\
\text { São Paulo }\end{array}$ \\
\hline $\begin{array}{l}\text { 9. O Telejornalismo Local e seus Modos de Produzir } \\
\text { sentidos em Educação Ambiental }\end{array}$ & $\begin{array}{l}\text { Universidade Federal do Espírito } \\
\text { Santo / Espírito Santo }\end{array}$ \\
\hline $\begin{array}{l}\text { 10. O Dispositivo da Educação Ambiental: modos de } \\
\text { Constitui-se Sujeito na Revista Veja }\end{array}$ & $\begin{array}{l}\text { Universidade Federal do Rio Grande } \\
\text { do Sul / Rio Grande do Sul }\end{array}$ \\
\hline $\begin{array}{l}\text { 11. Análise de mídias audiovisuais sob a perspectiva } \\
\text { da Educação Ambiental crítica e dos professores da } \\
\text { educação básica' }\end{array}$ & $\begin{array}{c}\text { Universidade de São Paulo (USP) / } \\
\text { São Paulo }\end{array}$ \\
\hline $\begin{array}{l}\text { 12. Comunicação e Educação Ambiental: uma } \\
\text { análise de conteúdo da revista XXI Ciência para a } \\
\text { Vida da Embrapa }\end{array}$ & $\begin{array}{l}\text { Universidade Estadual Paulista Júlio } \\
\text { de Mesquita Filho (Unesp) / São Paulo }\end{array}$ \\
\hline $\begin{array}{l}\text { 13. Estado da arte das produções na Revista } \\
\text { Brasileira de Educação Ambiental de } 2010 \text { a } 2016\end{array}$ & $\begin{array}{l}\text { Universidade Estadual do Oeste do } \\
\text { Paraná (Unioeste) / Paraná }\end{array}$ \\
\hline
\end{tabular}

Fonte: As Autoras, 2019.

\section{Abordagens}

Nosso estudo revelou que os trabalhos têm áreas específicas de abordagem. Dividimos essas abordagens em quatro categorias, conforme 
mostra o Quadro 3, as quais ordenamos levando em conta o maior número de registros:

1) Trabalhos que abordam direta ou indiretamente a EA nas escolas ou instituições de ensino, envolvendo o uso de mídias para o seu desenvolvimento, o que é chamado por muitos autores de Educomunicação. Essa abordagem ocorreu em 05 dos 13 trabalhos.

2) Trabalhos que abordam a EA na produção da mídia que se intitula especializada em meio ambiente. Encontramos 03 registros com essa característica;

3) Trabalhos que abordam a produção da mídia, não especializada, no seu aspecto de promover ou não EA nos seus conteúdos. Esses trabalhos, os quais encontramos 03 produções, são os que mais se aproximam do nosso objeto de pesquisa;

4) E trabalhos que abordam a produção de mídias especializadas em educação, abordagem na qual foram encontrados dois registros.

Quadro 3: Quadro das Categorias em que se enquadram as Teses e Dissertações que envolvem a temática Mídia e Educação Ambiental, selecionados nos bancos de dados Capes e BDTD, no período 2010 e 2018.

\begin{tabular}{|c|c|}
\hline Trabalho & Categoria \\
\hline $\begin{array}{l}\text { 1. Telejornalismo e Educação Ambiental: formação do sujeito } \\
\text { consumidor }\end{array}$ & $\begin{array}{l}\text { EA na Mídia especializada } \\
\text { em meio ambiente }\end{array}$ \\
\hline $\begin{array}{l}\text { 2. Mídia como instrumento de educação e de formação da consciência } \\
\text { ambiental abordagens na educação tecnológica }\end{array}$ & Educomunicação \\
\hline 3. A revista nova escola e as tendências em Educação Ambiental & $\begin{array}{l}\text { EA na Mídia especializada } \\
\text { em educação }\end{array}$ \\
\hline 4. O Discurso das Mudanças Climáticas no Diário Catarinense & $\begin{array}{l}\text { EA nas Mídias não } \\
\text { especializadas }\end{array}$ \\
\hline $\begin{array}{l}\text { 5. Representações Sociais de Educação Ambiental para estudantes: } \\
\text { Jornalismo como estratégia pedagógica }\end{array}$ & Educomunicação \\
\hline $\begin{array}{l}\text { 6. Comunicação, Cultura e Linguagem: o rádio como instrumento para } \\
\text { a prática de Educação Ambiental na Província do Cunene (República } \\
\text { de Angola) }\end{array}$ & $\begin{array}{l}\text { EA na Mídia especializada } \\
\text { em meio ambiente }\end{array}$ \\
\hline $\begin{array}{l}\text { 7. Mídia em Educação Ambiental: O uso do recurso tecnológico } \\
\text { audiovisual no cotidiano escolar }\end{array}$ & Educomunicação \\
\hline $\begin{array}{l}\text { 8. A Prática de Educação Ambiental no âmbito do ensino formal: } \\
\text { estudos publicados em revistas Acadêmicas Brasileiras (2007 a 2012) }\end{array}$ & Educomunicação \\
\hline $\begin{array}{l}\text { 9. O Telejornalismo Local e seus Modos de Produzir sentidos em } \\
\text { Educação Ambiental }\end{array}$ & $\begin{array}{l}\text { EA nas Mídias não } \\
\text { especializadas }\end{array}$ \\
\hline $\begin{array}{l}\text { 10. O Dispositivo da Educação Ambiental: modos de Constitui-se } \\
\text { Sujeito na Revista Veja }\end{array}$ & $\begin{array}{l}\text { EA nas Mídias não } \\
\text { especializadas }\end{array}$ \\
\hline $\begin{array}{l}\text { 11. Análise de mídias audiovisuais sob a perspectiva da Educação } \\
\text { Ambiental crítica e dos professores da educação básica' }\end{array}$ & Educomunicação \\
\hline $\begin{array}{l}\text { 12. Comunicação e Educação Ambiental: uma análise de conteúdo da } \\
\text { revista XXI Ciência para a Vida da Embrapa }\end{array}$ & $\begin{array}{l}\text { EA na Mídia especializada } \\
\text { em meio ambiente }\end{array}$ \\
\hline $\begin{array}{l}\text { 13. Estado da arte das produções na Revista Brasileira de Educação } \\
\text { Ambiental de } 2010 \text { a } 2016\end{array}$ & $\begin{array}{l}\text { EA na Mídia especializada } \\
\text { em educação }\end{array}$ \\
\hline
\end{tabular}

Fonte: As Autoras (2019). 
A Figura 4 apresenta a existência de uma predominância de trabalhos voltados para Educomunicação. A prática implica na implementação de políticas de comunicação educativa, que têm como objetivo geral o planejamento, a criação e o desenvolvimento de ecossistemas educativos mediados por processos de comunicação e pelo uso das tecnologias da informação (SOARES, 2004).

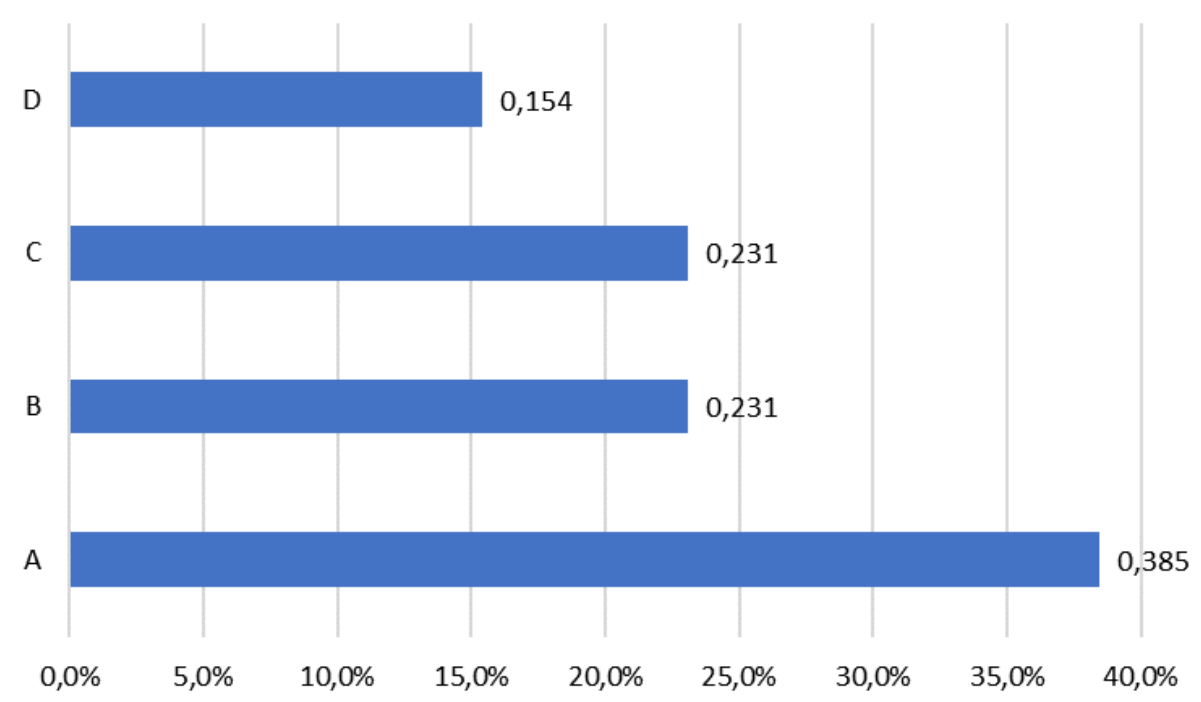

$\mathbf{A}=$ Educomunicação; $\mathbf{B}=\mathrm{EA}$ na Mídia Especializada em meio ambiente; $\mathbf{C}=\mathrm{EA}$ na Mídia não especializada; $\mathbf{D}=E A$ na Mídia especializada em educação.

Figura 4: Percentual das categorias nos quais se encontram os trabalhos que envolvem o campo temático Educação Ambiental e mídia, selecionados nos bancos de dados Capes e BDTD, no período entre 2010 e 2018.Fonte: As Autoras (2019).

O Programa de Educomunicação Sociambiental do Ministério do Meio Ambiente relata, com base na conclusão de pesquisa sobre a relação Comunicação/Educação, coordenada pelo professor Ismar de Oliveira Soares junto ao Núcleo de Comunicação e Educação da Universidade de São Paulo (USP/NCE), entre 1997 e 1999, que o termo Educomunicação passou a ser usado para designar não apenas os esforços em torno da leitura crítica das mensagens midiáticas, mas as ações que compõem o complexo campo da inter-relação Comunicação e Educação. Soares apresentou academicamente o termo sem, contudo, criar uma nova área de conhecimento, mas tentando legitimar práticas dos comunicadores populares e sistematizar o movimento social em torno do que até então também era chamado de comunicação/educação ou inter-relação comunicação e educação.

Para Soares, o campo da Educomunicação, portanto, é o resultado da inter-relação entre a Comunicação e a Educação e abrange quatro áreas de intervenção: (a) a educação para os meios, que promove reflexões e forma receptores críticos; (b) o uso e manejo dos processos de produção midiática; 
(c) a utilização das tecnologias de informação/comunicação no contexto ensino/ aprendizagem; e (d) a comunicação interpessoal no relacionamento entre grupos.

Educação e mídia têm em comum o potencial de empoderar as pessoas porque suas bases são fundamentadas no conhecimento e no saber.

Ao se analisar as relações que se estabelecem entre mídia e educação, fica evidenciada a forte influência que os meios de comunicação vêm exercendo constantemente sobre os processos de ensino. Mesmo que possam ser reconhecidas, em vários aspectos, como instâncias antagônicas e possuidoras de interesses distintos, mídia e educação guardam entre si algumas semelhanças, destacando-se o fato de se constituírem em elementos por onde se processa, permanentemente, a circulação do saber (TEIXEIRA, 2011, p. 80).

Os trabalhos estudados apontam a necessidade de formação continuada para os professores, e, dentro dessa formação, a obtenção de conhecimento no lidar com os instrumentos de comunicação de forma a maximizar a utilização pedagógica deles. Segundo Mezzari (2012, p.112),

Nos dias de hoje, é necessário que, nós professores, tenhamos uma visão crítica a respeito da mídia, desenvolvendo uma visão consciente do seu papel social. Somos muitas vezes formadores de opiniões, daí a importância da reflexão na presença dos meios de comunicação. Ter uma consciência crítica, partindo da realidade e da dinâmica do conhecimento, é fundamental. Antes de qualquer coisa, deve-se repensar a educação, suas fontes, seus conhecimentos e a forma de inclusão dos meios de comunicação nesse processo. Para tanto, necessitamos da formação continuada desses profissionais

Os trabalhos sobre Educomunicação apontam que os educadores precisam buscar metodologias significativas, criativas e alternativas de EA, "de modo a associarem teoria e prática, e, ao mesmo tempo, ampliarem seus olhares em torno do real sentido de EA" (MEZZARI, 2012, p. 11). Eles ressaltam também a importância de dominar a informação para poder transformar as relações da sociedade com o meio ambiente: "o domínio da informação está diretamente ligado ao poder de interferir e reorientar as relações humanas e da sociedade com a natureza" (PEREIRA, 2011, p.18).

Com relação às concepções de EA praticadas pela mídia, observamos nos trabalhos que se inseriram nas três categorias que envolvem, especificamente, EA e Mídia, que a mais utilizada é a pragmática. Esse tipo de 
prática de EA propõe somente uma intervenção solucionadora do problema, sem se preocupar muito com a causa dele, apresenta foco na ação, na busca de soluções para os problemas ambientais e em propostas de normas a serem seguidas para resolver as questões (SILVA, 2007). Conforme Crespo (1998) essa categoria de EA pode ter suas raízes no ambientalismo pragmático ou ecologia de resultados.

Silva (2007) estabelece três tipos de concepções de EA: a conservadora, a pragmática e a crítica. De acordo com a autora, a primeira busca transmitir conhecimentos ambientais, acreditando que essas informações possam contribuir para a geração de mudanças de atitudes. A segunda - detectada como a mais praticada pela mídia na nossa pesquisa -, incorpora a ação individual ou coletiva, embora de maneira pontual, como forma de possibilitar o desenvolvimento sustentável, mas não leva em conta os conflitos socioambientais. E a terceira, a crítica, busca a transformação social através da reflexão e ação sobre os conflitos ambientais, identificando e responsabilizando os setores sociais que respondem pela degradação ambiental e pela injustiça social.

$\mathrm{Na}$ Dissertação Telejornalismo e Educação Ambiental: formação do sujeito consumidor, um dos trabalhos estudados, é explicitado que são raros os momentos em que se notaram traços de EA crítica nos telejornais especializados em meio ambiente. A concepção crítica parte do princípio que o homem integra a natureza com singularidades que o diferem de outras espécies, sem que isso se induza a uma concepção do homem fora da natureza ou um ser biológico dissociado do natural (PEREIRA, 2010).

A EA crítica é colocada por muitos estudiosos como, efetivamente, capaz de promover uma transformação do modus operandi da sociedade com relação ao meio ambiente. Loureiro (2009) diz não serem aceitáveis, a partir da compreensão de uma EA emancipatória e transformadora, soluções que tentem compatibilizar meio ambiente e capitalismo - que na sua avaliação são incompatíveis - ou ainda opções moralistas que desvinculem 0 fator comportamental do fator histórico-cultural da estruturação da sociedade.

$\mathrm{Na}$ nossa pesquisa ficou explícita a capacidade da mídia em construir discursos, que seriam oficializados - no sentido de ganhar credibilidade popular - pela estatística. Para Garré (2015) a fabricação dos discursos ocorre a partir dos enunciados, e são legitimados com o auxílio de saberes, como os números explicitados pela estatística.

Também verificamos que a Teoria do Agendamento ou hipótese da agenda setting - teoria da comunicação cujo pressuposto fundamental é que a compreensão que as pessoas têm de grande parte da realidade lhes é fornecida pela mídia (WOLF, 2002) -, funciona, ou seja, muitas vezes a sociedade é, efetivamente, agendada pela mídia. Segundo Crispim (2003, p. 75 e 76), 
É sabido que os debates realizados socialmente têm como tema, em grande parte, o que é retratado pela imprensa como importante e 'digno de nota'. Isso se deve, especialmente, ao fato de que é raro o contato primário pelos integrantes do público com todos os acontecimentos noticiados diariamente. A dependência da sociedade com o trabalho da imprensa é reconhecida em função dessa impossibilidade, derivada diretamente da abrangência de eventos com os quais lidam os jornalistas.

Ao longo deste levantamento do estado da arte foi constatado ainda que há o reconhecimento da importância da mídia na divulgação dos temas ambientais e do seu potencial de educadora ambiental. "É com grande influência dos meios de comunicação que a humanidade, hoje, toma contato com os problemas ambientais e procura rediscutir seus modelos de desenvolvimento e sua atuação no meio ambiente" (PEREIRA, 2011, p. 18). Como é externado no trabalho que investiga a produção noticiosa do Jornal Diário Catarinense sobre mudanças climáticas, há consenso acadêmico e científico sobre o papel do jornalismo no exercício da sua função de reforçar a cidadania para o aperfeiçoamento do debate público (DEROSA, 2013).

Por outro lado, inferimos também que há uma fragmentação e uma descontextualização na forma como a mídia trata os temas relacionados ao meio ambiente. Existem aspectos ideológicos, políticos e mercadológicos que envolvem os meios de comunicação de massa, que muitas vezes não contribuem para que possam ser feitas análises mais aprofundadas dos temas tratados.

\section{Conclusão}

O estudo realizado demonstrou que ainda é incipiente a produção de pesquisa no campo temático EA e Mídia, bem como os entraves que a mídia tem para aprofundar suas abordagens, seja por questões ideológicas, políticas ou de mercado. Também foi possível evidenciar que a maioria dos trabalhos se voltam para pesquisas sobre o uso das mídias como instrumento de educação nos estabelecimentos de ensino (Educomunicação). E que um número reduzido aborda, efetivamente, a forma como a mídia trata as questões ambientais, se cumpre ou não o papel de educadora ambiental na sua produção diária de notícias. Papel, inclusive, previsto na Lei 9.795/9, que institui a Política Nacional de Educação Ambiental.

Como deixamos claro na introdução deste trabalho, nosso objetivo nesta pesquisa era traçar o estado da arte, isto é, "sondar o terreno" do campo de pesquisa EA e Mídia para podermos, se possível, avançar nesta área. O que apresentamos e discutimos dão-nos firmeza no propósito do nosso objeto de estudo, porque revelam que este é ainda um campo fértil para pesquisas, o que mostra que esta área de conhecimento tem ainda um horizonte amplo a ser descortinado. 


\section{Agradecimentos}

A Fundação de Amparo à Pesquisa do Estado de Goiás (FAPEG), pelo apoio financeiro à pesquisa, ao Instituto do Meio Ambiente e dos Recursos Hídricos do Distrito Federal - Brasília Ambiental (IBRAM) pela concessão de licença para estudo. Ao Programa de Pós-Graduação em Sociedade, Tecnologia e Meio Ambiente (PPG STMA) e ao Núcleo de Educação Ambiental (NEA), ambos do Centro Universitário de Anápolis, Goiás, por tornarem possível a realização da pesquisa.

\section{Referências}

ARIEIRA, A.A.S. Representações Sociais de Educação Ambiental para estudantes: jornalismo como estratégia pedagógica. Dissertação (Mestrado Profissional em Ensino em Ciências da Saúde e do Meio Ambiente) - Curso de Pós-graduação em Ensino em Ciências da Saúde e do Meio Ambiente. Fundação Oswaldo Aranha Centro Universitário de Volta Redonda. 2013. $85 f$. Disponível em: <http://sites.unifoa.edu.br/portal ensino/mestrado/ mecsma larquivos/2013/7.pdf> Acesso em: 12/12/2018.

BACIC, M.C. Análise de mídias audiovisuais sob a perspectiva da Educação Ambiental crítica e dos professores da educação básica. Dissertação (Mestrado em Ensino de Ciências) - Curso de Pós-Graduação em Ensino de Ciências, 2017. 268 f. Universidade de São Paulo. Disponível em: $<$ http://www.teses.usp.br/teses/disponiveis/81/81133/tde-08052019-150456/es. php>. Acesso em 14/12/2018.

BARBIERI, J.C. Gestão Ambiental empresarial: conceitos, modelos e instrumentos. São Paulo: Saraiva, 2011.

BRASIL. Programa Nacional de Educação Ambiental. Educomunicação socioambiental: comunicação popular e educação. Disponível em: <https://mma.gov.br/estruturas/educamb/ arquivos/txbase educom 20.pdf> Acesso em: 10/12/2018.

BRASIL. Lei 9.795 de 27 de abril de 1999. Disponível em: <https://mma.gov.br/estruturas/educamb/ arquivos/txbase educom 20.pdf> Acesso em: 10/12/2018.

BRASIL. Programa de Educomunicação Socioambiental. Disponível em: $<$ http://www.mma.gov.br/estruturas/educamb/ arquivos/dt 02.pdf> Acesso em: 08/04/2019.

BORBA, M. C; PENTEADO, M.G. Informática e Educação Matemática. $2^{\mathrm{a}}$ ed. Belo Horizonte - MG: Editora Autêntica, 2001.

BUENO, W.C. Comunicação, jornalismo e meio ambiente: teoria e pesquisa. São Paulo: Mojoara Editorial, 2007. 
CHAGAS, M.F. Mídia em Educação Ambiental: o uso do recurso tecnológico audiovisual no cotidiano escolar. Dissertação (Mestrado em Ciências da Saúde e do Meio Ambiente) - Curso de Pós-Graduação em Saúde e Meio Ambiente, Centro Universitário Plínio Leite. Rio de Janeiro, RJ. 2013. $161 \mathrm{f}$.

COGO, M.F. O Telejornalismo local e seus modos de produzir sentidos em Educação Ambiental. Tese (Doutorado em Educação) - Programa de PósGraduação em Educação, Universidade Federal do Espírito Santo. 2015. $201 \mathrm{f}$. Disponível em: <http://repositorio.ufes.br/handle/10/2239>. Acesso em: 10/11/2018.

CRESPO, S. Educar para a sustentabilidade: a Educação Ambiental no Programa da Agenda 21. In: NOAL, F.O.; REIGOTA M.; BARCELOS, V.H.L (Org). Tendências da Educação Ambiental Brasileira. Santa Cruz do Sul: EDUNISC, 1998.

CRISPIM, R.B. Estratégias singulares de agendamento: 0 caso do Greenpeace. Comunicação \&. Informação. Goiânia, v 6 n. 2 maio 2003.

DEROSA, C.M. O Discurso do Tema das Mudanças Climáticas e Aquecimento Global no Jornal Diário Catarinense. Dissertação (Mestrado em Jornalismo) Programa Pós-Graduação em Jornalismo da Universidade Federal de Santa Catarina. 2013. 108f. Disponível em: <https://repositorio.ufsc.br/handle/ 123456789/123134>. Acesso em: 14/12/2018.

FERREIRA, N.S.A. As Pesquisas denominadas o "Estado da Arte". Educação \& Sociedade. São Paulo, n.79, agosto 2002.

FREIRE, P. Pedagogia da Autonomia: saberes necessários à prática educativa. Rio de Janeiro - RJ: Paz e Terra, 1996.

GADOTTI, M. Ecopedagogia e educação para a sustentabilidade. Disponível em: <http://www.biologia.ufrj.br/ereb-se/artigos/ecopedagogia e educacao.pdf>. Acesso em: 08/04/2019.

GARRÉ, B.H. O Dispositivo da Educação Ambiental: Modos de Constituir-se Sujeito na Revista Veja. Tese (Doutorado em Educação Ambiental) Programa de Pós-Graduação em Educação Ambiental, Fundação Universidade Federal do Rio Grande. 2015. 186 f. Disponível em: <http://repositorio. furg.br/handle/1/6006> Acesso 10/12/2018.

LEFF, E. Epistemologia Ambiental. 5쪼 ed. São Paulo - SP: Cortez, 2010.

LOUREIRO, C.F.B. Educação Ambiental e Teorias Críticas. In: GUIMARÃES, M (Org.). Caminhos da Educação Ambiental: da forma à ação. Campinas: Papirus, 2006.

KREUZ, A.M. Estado da Arte das Produções na Revista Brasileira de Educação Ambiental de 2010 a 2016. Dissertação (Mestrado em Geografia) - Programa de Pós-Graduação em Geografia, Universidade Estadual do Oeste do Paraná. 2018. 165f. Disponível em: <http://tede.unioeste.br/ handle/tede/3756>. Acesso em: 10/12/2018. 
MARTINS, M.C. Educação Ambiental: um estudo de caso na Escola Municipal de Ensino Fundamental Jorge Bif. Criciúma, SC: Ed. do Autor, 2009.

MEZZARI, S. A revista Nova Escola e as tendências em Educação Ambiental. Dissertação (Mestrado em Educação) - Programa de Pós-Graduação em Educação, Universidade do Extremo Sul Catarinense, 2012. 118f. Disponível em: <http://repositorio.unesc.net/handle/1/1052>. Acesso em: 02/12/2018.

MORALES, A.G. A formação do profissional educador ambiental: reflexões, possibilidades e constatações. Ponta Grossa - PR: Ed. UEPG, 2012.

MORIN, E. Os sete saberes necessários à educação do futuro. $2^{\circ}$ ed. São Paulo - SP: Cortez, 2011

PEREIRA, C.L. Telejornalismo e Educação Ambiental: formação do sujeito consumidor? Dissertação (Mestrado em Desenvolvimento Sustentável) Programa de Pós-Graduação em Desenvolvimento Sustentável, Universidade de Brasília. 2010. 120f. Disponível em: <http://repositorio.unb.br/handle/ 10482/7998 > Acesso em: 01/12/2018.

PITANGA, A.F. 0 enfrentamento da crise socioambiental: Um diálogo em Enrique Leff sobre a racionalidade e o saber ambiental. Revista Eletrônica do Mestrado em Educação Ambiental. v. 32. N. 1 dez. 2015.

PORTO, R.G.C. O Uso da Mídias na Educação Ambiental. Especialização (Especialização em Mídias para a Educação) Curso Lato Sensu em Mídias para Educação, Centro Interdisciplinar de Novas tecnologias na Educação, Universidade Federal do Rio Grande do Sul. 2015. 39 f. Disponível em: $<$ https://www.lume.ufrgs.br/bitstream/handle/10183/134409/000986784.pdf?seq uence $=1>$ Acesso em: 10/11/2018.

REIGOTA, M. Verde cotidiano: o meio ambiente em discussão. 2.ed. Rio de Janeiro - RJ: DP\&A, 2001.

SANTOS, F.F. Comunicação e Educação Ambiental: uma análise de conteúdo da revista XXI Ciência para a Vida da Embrapa. Dissertação (Mestrado em Agronegócio e Desenvolvimento da Faculdade de Ciências e Engenharia) Universidade Estadual Paulista Júlio de Mesquita Filho. 2017. 234f Disponível em: <https://repositorio.unesp.br/handle/11449/150769> Acesso em: 02/12/2018.

SILVA, D. A. B. M. A mídia a serviço da educação: a revista Nova Escola. Marília: UNIMAR, 2009.

SILVA, R.L.F. O meio ambiente por trás da tela - estudo das concepções de Educação Ambiental dos filmes da TV escola. Tese (Doutorado em Educação) - Faculdade de Educação, Universidade de São Paulo. 2007. 208f. Disponível em: $\quad<$ http://www.teses.usp.br/teses/disponiveis/48/48134/tde-25042007104315/>. Acesso em: 10/01/2018.

SOARES, I.O.S. Educommunication. São Paulo - SP: NCE-ECA/USP. 2004. 
SOARES, M. Alfabetização no Brasil - O Estado do conhecimento. Brasília DF: INEP/MEC, 1989.

TEIXEIRA, F. Mídia como instrumento de educação e de formação da consciência ambiental "abordagens na educação tecnológica". Tese (Doutorado em Educação). Programa de Pós-Graduação em Educação Científica e Tecnológica, Universidade Federal de Santa Catarina. 2011. $267 f$. Disponível em: https://repositorio.ufsc.br/xmlui/handle/123456789/95502 Acesso em: 10/12/2018.

TOZONI-REIS, M.F.C. Formação dos educadores ambientais e paradigmas em transição. Ciência \& Educação. Bauru, v. 8, n. 1, p. 83-96, 2002.

TRAJBER, R. Educomunicação para coletivos educadores. Brasília - DF: MMA, 2005.

TRISTÃO, M. A Educação Ambiental na formação de professores: redes de saberes. São Paulo - SP: Annablume; Vitória - ES: Facitec, 2008.

VIEGAS, P.L. A prática de Educação Ambiental no âmbito do ensino formal: estudos publicados em revistas acadêmicas brasileiras (2007 a 2012). Dissertação (Mestrado em Sustentabilidade na Gestão Ambiental) - Programa de Pós-Graduação em Sustentabilidade na Gestão Ambiental, Universidade Federal de São Carlos. 2014. 133f. Disponível em: http://www.ppgsga.ufscar.br /alunos/banco-de-dissertacoes/2014/dissertacao-patricia-de-lourdes-viegas.pdf Acesso em: 12/12/2018. 